\title{
INOVASI KEGIATAN DESA JATIMULYO KECAMATAN JATI AGUNG KABUPATEN LAMPUNG SELATAN “GRUP ASIK (GRUP ASI EKSLKLUSIF)”
}

\author{
Ledy Octaviani Iqmy ${ }^{1}$, Ratna Dewi Putri² \\ ladyunimal@gmail.com ${ }^{1}$, ratnadewi.070787@gmail.com² \\ ${ }^{12}$ Program Studi Kebidanan Universitas Malahayati
}

\begin{abstract}
ABSTRAK
Menyusui adalah suatu proses alamiah. Berjuta-juta ibu diseluruh dunia berhasil menyusui bayinya tanpa pernah membaca buku tentang ASI. Bahkan ibu yang buta huruf pundapat menyusui anaknya dengan baik. Walaupun demikian, dalam lingkungan kebudayaan kita saat ini melakukan hal yang alamiah tidaklah selalu mudah. Kegiatan ini dilakukan atas dasar kurang nya pengetahuan ibu hamil dan ibu menyusui terhadap pemberian ASI Eksklusif pada bayi, didapatkan data status bekerja ibu dapat mengurangi minat dalam memberi ASI Eksklusif selama 6 bulan. Maka dari itu dibuatlah inovasi Grup ASIK (ASI Eksklusif) yang bertujuan untuk meningkatkan pengetahuan, pemahamaan, informasi maupun solusi terhadap pemberian ASI Eksklusif pada bayi berusia 0-6 bulan. Grup ASIK beranggotakan Ibu-ibu hamil, Ibu-ibu menyusui atau ibu yang memiliki Bayi 0-6 bulan,yang kemudian dipandu oleh Bidan Desa sebagai Motivator sekaligus menentukan tindak lanjut, sedangkan kader bertugas untuk mengumpulkan data ibu-ibu yang akan bergabung di Grup ASIK. Diharapkan ibuibu merasa nyaman, merasa didukung, dicintai, dan diperhatikan, sehingga membuat produksi hormon oksitosin meningkat untuk melancarkan produksi ASI

Dilakukan kegiatan penyuluhan inovasi Grup ASIK pada tanggal 31 Maret 2021 di Dusun III RT 30di Desa Jatimulyo Kecamatan Jatiagung Kabupaten Lampung Selatan. Hasilnya ibu-ibu peserta penyuluhan mengalami peningkatan pengetahuan mengenai pentingnya pemberian ASI Eksklusif pada bayi dari umur 0-6 bulan. Bidan desa Jatimulyo beserta kader bersedia melanjutkan inovasi Grup ASIK (Asi Eksklusif), dengan cara mengajak Ibu-Ibu hamil dan menyusui untuk bergabung dengan Grup ASIK. Ibu menyusui semakin terbuka terhadap masalah yang dihadapi ibu selama memberikan ASI Eksklusif dan mau berbagi pengalaman dalam Grup, sehingga dapat diberikan solusi oleh Bidan Desa maupun kader setempat untuk ditindak lanjuti.
\end{abstract}

Kata Kunci: Ibu Hamil,Grup ASIK, ASI Eksklusif

\section{ABSTRACT}

Breastfeeding is a natural process. Millions of mothers around the world successfully breastfeed their babies without ever reading books about breastfeeding. Even illiterate mothers can breastfeed their children well. However, in our cultural environment today doing the natural thing is not always easy. This activity is carried out on the basis of the lack of knowledge of pregnant women and breastfeeding mothers on exclusive breastfeeding for babies, data on the work status of mothers can reduce their interest in exclusive breastfeeding for 6 months. Therefore, the innovation of the ASIK Group (Exclusive ASI) was created which aims to increase knowledge, understanding, information and solutions to exclusive breastfeeding for infants aged 0-6 months. The ASIK group consists of pregnant women, breastfeeding 
mothers or mothers who have babies 0-6 months, who are then guided by the Village Midwife as a Motivator as well as determining follow-up, while cadres are tasked with collecting data on mothers who will join the ASIK Group. It is hoped that mothers feel comfortable, feel supported, loved, and cared for, thereby increasing the production of the hormone oxytocin to accelerate ASI production.

ASIK Group innovation counseling activities were carried out on March 31, 2021 at Dusun III RT 30 in Jatimulyo Village, Jatiagung District, South Lampung Regency. As a result, the mothers participating in the education have increased their knowledge about the importance of exclusive breastfeeding for babies from 0-6 months of age. Jatimulyo village midwives and cadres are willing to continue the innovation of the ASIK Group (Exclusive ASI), by inviting breastfeeding women and pregnant women to join the ASIK Group. Breastfeeding mothers are increasingly open to problems faced by mothers during exclusive breastfeeding and are willing to share experiences in the group, so that solutions can be provided by the Village Midwives and local cadres to be followed up.

KeyWord : Pregnant women, Grup ASIK, Exclusive ASI

\section{PENDAHULUAN}

World Health Organization (WHO) membuat deklarasi yang dikenal dengan Deklarasi Innocenti tahun 1990 tentang perlindungan, promosi, dan dukungan terhadap penggunaan ASI, disepakati pula untuk pencapaian pemberian ASI Eksklusif sebesar $80 \%$ pada tahun 2000. Deklarasi ini juga ditandatangani oleh Indonesia sebagai tujuan global untuk meningkatkan kesehatan dan mutu makanan bayi secara optimal, maka semua ibu dapat memberikan ASI eksklusif sejak lahir sampai berusia 4-6 bulan. Pada tahun 1999, setelah pengalaman selama 9 tahun UNICEF memberikan klarifikasi tentang rekomendasi jangka waktu pemberian ASI eksklusif. Rekomendasi terbaru UNICEF bersama World Health Asembly (WHA) dan banyak negara lainnya adalah menetapkan jangka waktu pemberian ASI eksklusif selama 6 bulan.

Berdasarkan hasil perhitungan data SUSENAS cakupan bayi mendapatkan ASI Ekslusif di Provinsi Lampung tahun 2013 sebesar 29,24\% dimana angka ini masih ada di bawah target yang diharapkan yaitu $80 \%$. Bila dilihat berdasarkan capaian per kabupaten kota tidak ada satupun kabupaten kota yang mencapai target yang diharapkan. Data diwilayah kerja Puskesmas Karang Anyar Lampung Selatan pada tahun 2019 data cakupan bayi yang mendapatkan ASI Eksklusif sebesar 69,3\%, sehingga sebesar 30,7\% tidak memberikan ASI kepada bayinya. Berdasarkan dari hasil SMD yang telah dilakukan di Dusun III RT 30 Desa Jatimulyo Kecamatan Jati Agung Lampung Selatan pada bulan Maret 2021 terdapat 2 orang ibu menyusui yang diwawancarai, terdapat 1 orang mengatakan tidak memberikan ASI Eksklusif kapada bayinya dan 1 orang Ibu lagi mengatakan tidak sempat memberikan ASI secara eksklusif dikarenakan bekerja.

Pengetahuan ibu, tingkat pendidikan ibu dan pekerjaan ibu merupakan urusan yang pentingdalam pemberian ASI eksklusif, memang membuat 
kerepotan menjadi lebih besar untuk seorang ibu dibandingkan menyerahkan kepada orang lain dengan susu kaleng justru kepuasan yang didapatkan akan bertambah jika dengan status bekerja ibu dapat memberi Asi eksklusif selama 6 bulan.

\section{MASALAH}

Desa Jatimulyo Kecamatan Jati Agung Kabupaten Lampung Selatan khususnya Dusun III RT 30. Kegiatan ini dilakukan atas dasar kurangnya pengetahuan ibu hamil dan ibu menyusui terhadap pemberian ASI Eksklusif pada bayi. Tujuan kegiatan agar meningkatkan pengetahuan dan pemahamaan ibu hamil yang terhadap pemberian ASI Eksklusif pada bayi umur 0-6 bulan.

\section{METODE}

Kegiatan telah dilaksanakan pada 31 maret 2021 pukul 10.00 wib. Subjek pada kegiatan ini 15 ibu hamil dan ibu menyusui di Dusun III RT 30 di Desa Jatimulyo Kecamatan Jati agung Kabupaten Lampung Selatan. Kegiatan dilakukan dengan cara memperlihatkan Video dan bersama-sama pada ibu hamil dan menyusui membaca BUKU KIA serta dilakukan penyuluhan serta musyawarah kepada ibu hamil. Tahap akhir dalam kegiatan ini adalah sesi Tanya jawab pada ibu hamil mengenai pengetahuan ibu tentang penting nyapemberianASI Eksklusif pada bayi umur 0-6 bulan.

\section{HASIL \& PEMBAHASAN}

Rangkaian kegiatan penyuluhan kepada ibu hamil dan ibu menyusui di Dusun III RT 30 Desa Jatimulyo Kecamatan Jati agung Kabupaten Lampung Selatan berjalan dengan lancar tanpa kendala. Penyuluhan ini diikuti oleh 15 peserta yang terdiri dari ibu hamil, kader serta bidan.Berikut dokumentasi pelaksanaan kegiatan:

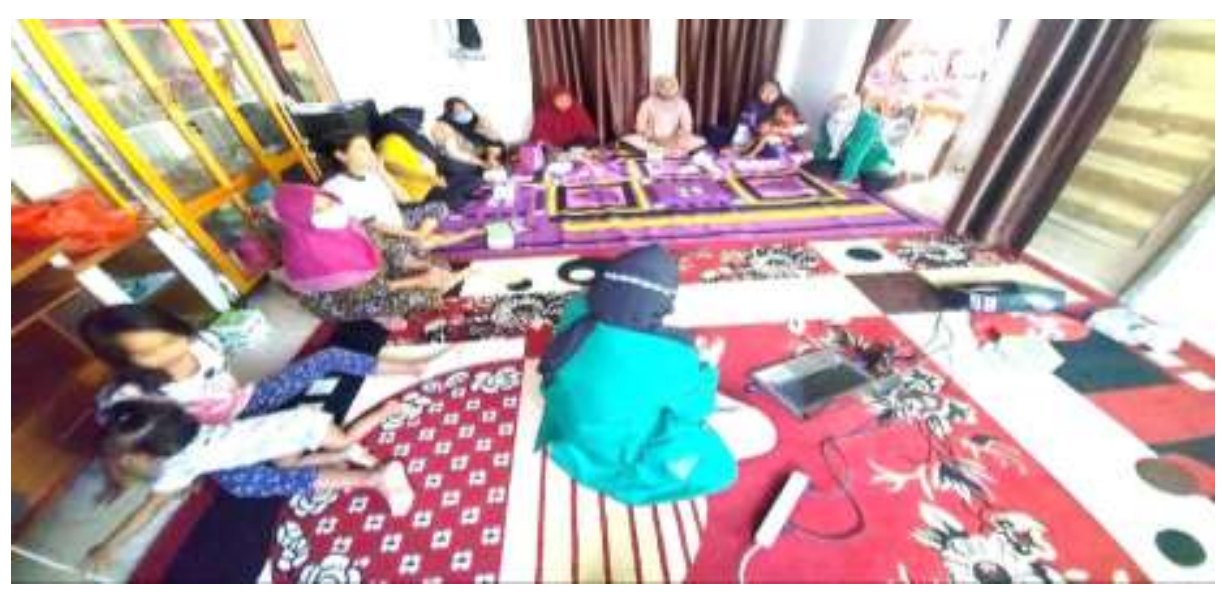




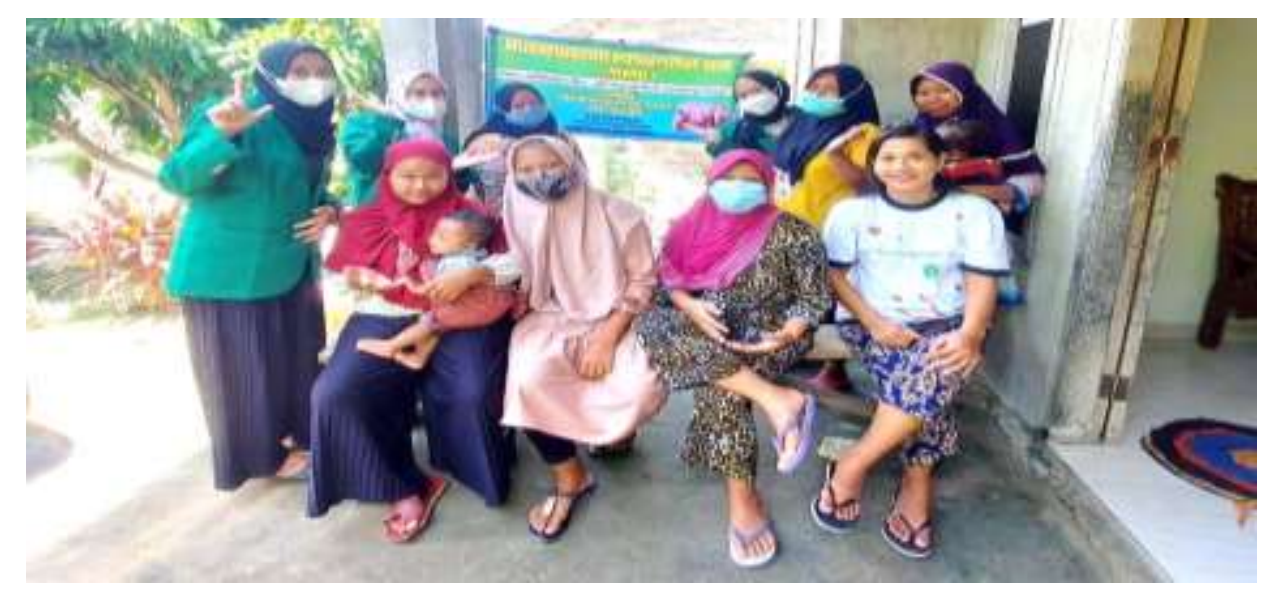

Peserta cukup antusias terhadap materi yang diberikan. Umpan balik yang diberikan cukup baik. Terdapat beberapa pertanyaan dan sanggahan dari peserta penyuluhan terkait materi yang telah diberikan. Materi yang telah diberikan cukup dipahami terbukti dari adanya peningkatan pengetahuan peserta menjawab pertanyaan yang benar.

\section{KESIMPULAN}

Kesimpulan dari kegiatan penyuluhan inovasi di Dusun III RT 30 Desa Jatimulyo KecamatanJati Agung Kabupaten Lampung Selatan adalah adanya peningkatan pengetahuan mengenai penting nya pemberian ASI Eksklusif pada bayi dari umur 0-6 bulan. Bidan desa Jatimulyo beserta kader bersedia melanjutkan inovasi Grup ASIK( ASI Eksklusif), dengan cara mengajak Ibu-lbu hamil menyusi untuk bergabung dengan Grup ASIK. Ibu menyusui semakin terbuka terhadap masalah yang dihadapi selama memberikan ASI Eksklusif dan mauberbagi pengalaman dalam Grup, sehingga dapat diberikan solusi oleh Bidan Desa maupun kader setempat untuk ditindak lanjuti.

\section{DAFTAR PUSTAKA}

Kurniasari, D., Putri, R. D., \& Hermawan, D. (2019). PENYULUHAN TUMBUH KEMBANG BALITA DI DESA JATIMULYO KABUPATEN LAMPUNG SELATAN. JURNAL PERAK MALAHAYATI, 1(1).

Iqmy,Octaviani L,. (2017) HUBUNGAN ANTARA PENGETAHUAN, PENDIDIKAN,

PEKERJAAN IBU YANG MEMPUNYAI BAYI UMUR 6-12 BULAN DENGAN

PEMBERIAN ASI EKSKLUSIF DI DESA PURWODADI KECAMATAN

GISTING KABUPATEN TANGGAMUS. JURNAL KEBIDANAN MALAHAYATI

Materinty, D., Sari, N. E., \& Halidesna, H. (2021). SOSIALISASI PEMBERIAN OLAHAN MAKANAN DARI DAUN KELOR (PUDING AGAR-AGAR, RISOLES, PUTU AYU DAUN KELOR) UNTUK MENINGKATAN DAN MEMPERLANCAR PRODUKSI ASI PADA IBU MENYUSUI DI DESA KALIASIN LAMPUNG SELATAN TAHUN 2021. JURNAL PERAK MALAHAYATI, 3(1), 13-20. 